\title{
NANOPHOTONIC LITHOGRAPHY: A VERSATILE TOOL FOR MANUFACTURING FUNCTIONAL THREE-DIMENSIONAL MICRO-/NANO-OBJECTS
}

\author{
M. Malinauskas, G. Kiršanskė, S. Rekštytė, T. Jonavičius, E. Kaziulionytė, L. Jonušauskas,
}

\author{
A. Žukauskas, R. Gadonas, and A. Piskarskas \\ Laser Research Center, Department of Quantum Electronics, Faculty of Physics, Vilnius University, Sauletekio 10, LT-10223 Vilnius, \\ Lithuania \\ E-mail: mangirdas.malinauskas@ff.vu.lt
}

Received 30 October 2012 ; accepted 20 December 2012

\begin{abstract}
In this paper, an overview of literature supported by original experimental results on direct laser polymerization of three-dimensional micro-/nano-structuring of various photopolymers is presented. Alternative technologies, principles of threshold based direct laser writing in polymers employing ultrafast lasers, issues of optimization of the laser structuring parameters for increasing fabrication resolution and production throughput are presented and discussed. Examples of woodpile templates and nanogratings are shown as well as an opto-fluidic sensor design for usage in lab-on-chip type devices is demonstrated and its performance is characterized. Additionally, a possibility to produce a three-dimensional electric circuit is introduced.
\end{abstract}

Keywords: ultrafast laser, 3D microfabrication, nanotechnology, lithography, photopolymers, photoresists, photonic crystals, optofluidics

PACS: $81.16 . \mathrm{Rf}, 85.85 .+\mathrm{j}, 42.70 . \mathrm{Jk}$

\section{Introduction}

Nonlinear absorption induced laser fabrication of true three-dimensional structures out of polymers with submicrometre spatial resolution was introduced a decade ago [1]. To date, this kind of direct laser writing based selective polymerization technique is already being applied widely in the fields of photonics, microoptics, micromechanics, micro-/nano-fluidics and transferred to production of artificial polymeric scaffolds, metamaterials and plasmonic devices [2-5]. Ultrafast laser direct writing being a branch of rapid prototyping techniques enables to form three-dimensional microstructures of complex geometry with $100 \mathrm{~nm}$ spatial resolution with unmatched flexibility (structure geometry and/or scale can be changed easily).

Direct laser polymerization is based on nonlinear light and matter interaction, when a pulsed light beam having high peak power from the range of vis- ible or near infrared wavelengths is tightly focused into the volume of a photosensitive polymer. Due to temporal and spatial overlap several photons are absorbed simultaneously at the beam waist. This is additionally maintained by linear absorption and thermal effects followed by further irreversible photochemical processes which are of threshold behaviour, like minimal concentration of photo-excited highly reactive radical molecules. The thresholding also arises from the post-processing of light exposed samples and depends on the material's chemical properties and the mechanical rigidity of the structure itself. In this way, by precisely tuning the intensity of light and exposure dose one can reach subdiffraction (up to $\lambda / 30$ ) spatial structuring resolution [6-10]. After the point-by-point exposure the trace of the scanned laser focus in the polymer part of the material becomes resistant to organic solvents. Applying proper developing and rinsing conditions to yield rigid structures, up to $100 \mathrm{~nm}$ reproducible 
spatial resolution can be achieved to form functional three-dimensional micro-/nano-objects. To date, direct laser polymerization offers a possibility to produce objects out of various photosensitive polymer materials such as acrylates, organic-inorganic hybrids and epoxies which are distinguished for assorted optical, mechanical, chemical as well as biological properties offering a possibility to tune the material to case specific application. Finally, direct laser polymerization set-up is not complicated to use and does not require clean-room or any additional facility costly in maintenance.

\subsection{State-of-the-art and future apllications}

The direct laser polymerization technique owns an enormous potential of possible applications in fabrication of three-dimensional functional micro-/ nano-devices, yet it is still in its early stages of development, especially concerning mass production of devices required by industry. In order to expand the practical applicability to reach the horizons of potential it is necessary to optimize laser source and exposure conditions, sample positioning and/or beam scanning control, photosensitive response of the material's as well as developing and post-development steps. For this goal it is a requisite to have a synergetic collaboration between interdisciplinary science fields, such as laser optics (including ultrafast laser phenomena), material sciences (material properties at nanoscale) and chemistry (femtochemistry and nano-scaled chemistry). All together this could lead to overcoming the challenges and offer a direct and single-step process to structure micro-/ nano-objects with $<100 \mathrm{~nm}$ spatial resolution in all three dimensions [11-15]. This would open a way not only to greatly minimize the size of nowadays used complex micro-devices, but also allow the creation of manmade materials with properties which are non-existing in the real world naturally, e. g. plasmonic metamaterials which would realize invisibility cloaking [16-18] or artificial black holes which could be employed for energy harvesting [19]. Production of bio-attractive and biodegradable scaffolds would enable one to control stem cell proliferation and differentiation sequenced by advances in tissue engineering and regenerative medicine [20-22]. Additionally, direct laser polymerization allows formation of complex shaped micro-/nano-devices on various surfaces and materials easing the integration of single elements into sophisticated systems like lab-on-chip (LOC) [23, 24] or micro-opto-electromechanical systems (MOEMS) [25, 26].

From very first demonstration of direct laser polymerization as a micro/nanostructuring technique it has drawn a great attention for prototyping photonic crystal templates [27, 28]. Recently, concentrated research is being done for its application in plasmonics and metamaterial production experiments [29-31]. Yet, only a few papers have been published showing the potential to create sophisticated microoptical devices as well as their integration into complex three-dimensional optical circuits. Artificial polymer scaffolds fabricated by employing direct laser polymerization were shown to be biocompatible in vitro, yet lacking in practical demonstration of their biological functioning as the common overall size of the scaffolds was less than $100 \mu \mathrm{m}$ which is too tiny for in vivo tests. Then, based on contemporary situation it was essentially meaningful to focus the research for the creation of functional micro-/nanodevices mainly on these topical vectors.

\section{Techniques for three-dimensional micro/ nanostructuring of materials}

The interest in down-scaled functional micro-/ nano-devices is growing steadily as low-cost and high-efficiency devices are being applied wider in everyday life. During the last decades, efforts in improving the fabrication methods of such components have advanced dramatically. UV lithography [32], electron beam lithography [33], X-ray lithography [34] and NanoImprint Lithography [35] techniques are widely used for nanostructuring; however, these methods are suffering from lack of flexibility, cost efficiency and sometimes are limited in true three-dimensional structuring. Recently, the development of novel, less expensive technical routes of three-dimensional fabrication in industrial applications have emerged. It is represented by ink jet and 3D printing [36, 37, dip coating [38] and selective laser sintering [39, 40] techniques. However, these methods are lacking fabrication resolution and are limited in restricted spectrum of usable materials. During the last decade, a nonlinear lithography technique employing ultrafast lasers has emerged as a direct laser polymerization structuring approach [1]. Illustrations showing the feasibility and flexibility of the method for production of 
three-dimensional microstructures are shown in the following sections. A comparison of direct laser polymerization and alternative technologies for micro/ nanostructuring is given in Table.

Direct three-dimensional writing in photopolymers enables rapid, flexible and cost efficient fabrication of microstructures required in the fields of photonics [41-43], micro-optics [44, 45], microfluidics [46, 47], biomedical components [48, 49] and tissue engineering [20, 22]. Compared to its anterior alternative, UV $\mu$-stereolithography [50, 51], it offers higher spatial resolution and easier fabrication of true three-dimensional structures [52, 53]. Novel hybrid materials are expected to ensure higher structuring resolution and control, optimized mechanical, optical and electrical or even magnetic properties [54, 55]. A possibility to selectively metalize these nanostructures provides an opportunity to make it applicable in plasmonics or metamaterial production [56-59]. Using the direct laser polymerization technique, nearly $100 \mathrm{~nm}$ spatial structuring resolution was demonstrated [60-62] (prototype systems are already commercially available [6366]), but conventionally the structures are not much bigger than several tens or hundreds of micrometres. It complicates the practical applications of nano-featured microstructures or even characterization of their properties. This implies that a demand of three-dimensional micro/nanostructures over a large area is still high [67-69]. For example, larger photonic crystals or microlens arrays can increase their applicability; artificial scaffolds have to be big enough for a biologist or surgeon for comfortable handling. It is worth mentioning that biocompatible as well as biodegradable polymers can be used [70, 71]. Furthermore, structure transfer can be realized by a soft-lithography (micromolding) technique; in this way the original structure can be replicated into another material onto another substrate without the need of an ultrafast laser [72]. As nowadays powerful amplified laser systems are available, the implementation of diffractive optical elements (DOE) could significantly increase the production throughput of periodic micro/nanostructures [73]. In this way the whole structures (or single layers) can be fabricated via single exposure [74, 75].

\section{Direct laser polymerization technique}

Nowadays, photopolymerization is an indispensable part of industrial processing for a vast variety of daily used and hi-tech products. Yet, the history of modern applications of photopolymerization on the industrial scale is relatively short compared to metallurgy and wood processing. First commercial applications of this technique in coatings started in early 1960s. Many new material systems, fitting a wide variety of possible industrial applications, were soon developed. Appropriate equipment allowing fast material photo- and thermocuring providing control over the process on the industrial scale was introduced. In the 1980s the application of this tech-

Table 1. Direct laser polymerization among alternative micro/nanofabrication technologies: typical dimensions of processing areas, spatial resolution limit, typical throughput, typical costs per fabricated part, flexibility to fabricate different structures, and three-dimensional structuring possibility.

\begin{tabular}{|c|c|c|c|c|c|c|}
\hline Technology & $\begin{array}{c}\text { Processing } \\
\text { area }\end{array}$ & Resolution & $\begin{array}{l}\text { Through- } \\
\text { put }\end{array}$ & $\begin{array}{l}\text { Cost per } \\
\text { sample }\end{array}$ & Flexibility & $\begin{array}{l}\text { 3D struc- } \\
\text { turing }\end{array}$ \\
\hline Optical lithography & wafer & $30 \mathrm{~nm}$ & rapid & low & low & no \\
\hline $\begin{array}{l}\text { Nanoimprint litho- } \\
\text { graphy }\end{array}$ & wafer & $10 \mathrm{~nm}$ & rapid & low & low & no \\
\hline Self-assembly & wafer & $100 \mathrm{~nm}-1 \mu \mathrm{m}$ & medium & low & low & low \\
\hline Ink-jet printer & $\mathrm{cm}$ & $50-100 \mu \mathrm{m}$ & medium & low & medium & medium \\
\hline$\mu$-stereolithography & $\mathrm{cm}$ & $10-100 \mu \mathrm{m}$ & medium & medium & medium & medium \\
\hline Laser sintering & $\mathrm{cm}$ & $50-200 \mu \mathrm{m}$ & medium & medium & medium & medium \\
\hline fs laser ablation & $\mathrm{mm} / \mathrm{cm}$ & $1-50 \mu \mathrm{m}$ & medium & medium & high & no \\
\hline $\begin{array}{c}\text { Direct laser poly- } \\
\text { merization }\end{array}$ & $\mathbf{m m}$ & $100 \mathrm{~nm}-10 \mu \mathrm{m}$ & medium & medium & high & high \\
\hline $\begin{array}{l}\text { e-/ion-beam litho- } \\
\text { graphy }\end{array}$ & $\mu \mathrm{m}$ & $10 \mathrm{~nm}$ & low & high & high & medium \\
\hline AFM printing & $\mu \mathrm{m}$ & $10 \mathrm{~nm}$ & low & high & medium & no \\
\hline
\end{tabular}


nique expanded till wide acceptance in industry as a rapid prototyping technology based photopolymerization. Stereolithography, also known as 3D printing, a technique allowing to create complex threedimensional models from photosensitive materials, was soon followed by $\mu$-stereolithography which according to the provided CAD design enabled to produce objects at microscale [76]. Polymerization is defined as a process of reacting monomer molecules together in a chemical reaction to form threedimensional networks or polymer chains. It can be initiated via energy introduced from light or heat. The photopolymerization is defined as a light induced chemical reaction of monomers or oligomers which results in a solid polymeric network. Modern material systems for photopolymerization contain two main components: a photoinitiator and a monomer (or a mixture of monomers and oligomers). Photoinitiators are the molecules which have low photo dissociation energy and are added to increase photosensitivity of material. Photopolymerization reactions that form a cross-linked network follow the characteristic steps of any chain polymerization mechanism: photoinitiation, propagation and termination. Then the sample is immersed in the developer bath to selectively remove the non-polymerized part of the material.

Photopolymerization is advantageous compared to thermal or mechanical polymerization routes due to the provision of spatial and temporal control of the initiation reaction through the control of illumination conditions. Thus point-by-point structuring enables "materialization" of a CAD model out of the photopolymer as shown in Fig. 1. It is worth mentioning that most of the photopolymers have just a slight change in the optical refractive index during polymerization and thus enable further structuring focusing the beam through the already produced structure. Additionally, some hybrid or epoxy materials are in gel or solid state while being processed and the photomodified areas are not floating but are fixed in space. This lets to flexibly choose the starting and the ending point of scanning without any restrains which is sometimes convenient for specific geometries.

A variety of lasers were successfully applied for direct laser polymerization in three dimensions at micro-/nano-scale. Traditionally a Ti:Sapphire laser was employed for that purpose, its common parameters were $\lambda=780-800 \mathrm{~nm}, \tau=20-200 \mathrm{fs}$,

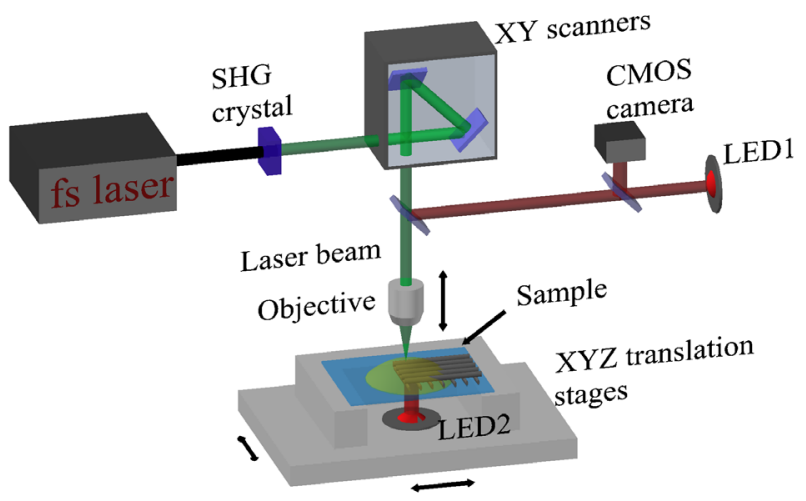

Fig. 1. The structure is inscribed in a point-by-point manner, as the localized photomodification follows the scanned contour of the focused laser beam. It changes the solubility of the material in organic solvents, thus after the development free-standing volumetric structures having intrinsic 3D geometry can be obtained.

$v=1 \mathrm{kHz}-80 \mathrm{MHz}$. At tight focusing conditions amplification of pulses is not necessary and femtosecond oscillator can be used [77]. However, by employing powerful pulses one can directly write inside non-photosensitized resins [78], thus avoiding an undesired photoinitiator, which can cause unwanted changes to the material (mostly because of photoinitiators being light absorbing and toxic compounds). Recently, demonstration of ps [79], ns [80] and even CW [81] applied for nanofabrication was reported. In most cases longer pulses narrow the spectra of the processable materials. On the contrary, extremely short pulses seem to influence the highest achievable spatial resolution [82], yet are more complicated to handle as they are more sensitive to the ambient conditions of the laboratory. Based on our experience, a pulse duration of several hundreds of femtoseconds and visible wavelengths are the most universal for efficient lithographic processing [83].

However, it still has drawbacks such as structure shrinkage and geometrical deformations. Shrinkage is a result of material densification compared to the original material formulation before polymerization. Since the amount of material before and after polymerization does not change, this density change will result in volume reduction corresponding to shrinkage [84]. Geometrical deformations occur when the structure is not rigid enough to withstand 
the developing and drying process. It is known that material rigidity is proportional to the volume of the material. Therefore, at micro-scale it would mean that a 10 times smaller feature would be $1000\left(\sim 10^{3}\right.$ lesser in volume) times fragile/soft. This becomes crucial when getting near to $100 \mathrm{~nm}$ spatial resolution in all three dimensions (confined volume of $\mathrm{fl})$. One more issue which is important for structure formation is the bulk material hardness. Usually it is better to apply harder material (with higher Young's modulus) in order to achieve lesser distortions, yet if the overall structure size increases, the material densification caused stress can induce mechanical cracks to release the accumulated tension. These questions were explained in a more detailed manner in Ref. [85].

The direct polymerization technique employing femtosecond lasers is based on point-by-point photomodification of the resin in space. It comes as a novel $\mu$-stereolithography technique based on nonlinear light-matter interaction (an analogue to laser scanning multiphoton microscopy). Spatial resolution of structured features is defined by the above threshold intensity distribution in the volume of the tightly focused laser beam waist. Precisely varying light intensity within the so-called fabrication window allows fine tuning of the voxel size. The fabrication window is defined as the $I_{\mathrm{d}} / I_{\text {th }}$ ratio, which is the intensity of the material optical damage divided by the threshold intensity required for polymerization (Fig. 2(a)). A wider fabrication window ensures easier photostructuring and enables to tune voxel size by changing laser intensity I (Fig. 2). By moving the sample relatively to the fixed focus spot one can photomodify the material along the scanning direction. Later, the sample (in case of a commonly used negative photopolymer it is a droplet on a substrate) is developed in organic solvent and the unexposed pre-polymer is washed out revealing a free-standing three-dimensional structure.

\subsection{Laser power (intensity)/translation velocity tuning for fabrication resolution scaling}

The simultaneous excitation mechanism involves a virtual intermediate state which is created by the first photon and the second photon which is absorbed only if it arrives within the virtual state life time of $10^{-15} \mathrm{~s}$ [86]. For this mechanism it is imperative to have a high intensity source which would ensure (a)
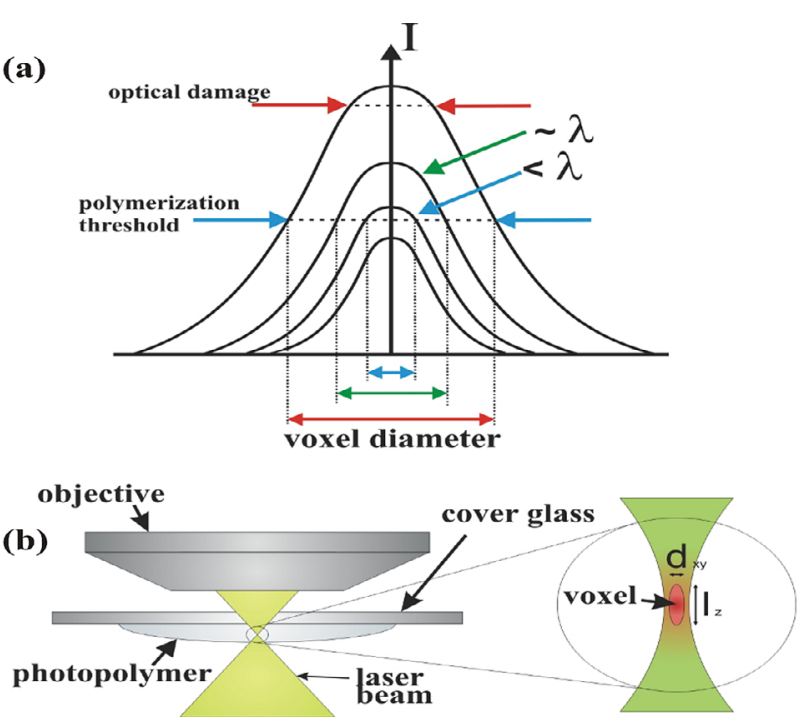

Fig. 2. (a) Fabrication is window and sub-wavelength resolution. The fabrication is window defined as $I_{\mathrm{d}} / I_{\mathrm{th}}$. By precisely adjusting the introduced laser intensity $I$ one can tune voxel dimensions and overcome the diffraction limit corresponding to the applied laser light wavelength. (b) Voxel size and aspect ratio. Voxel size follows light intensity distribution and has a form of an ellipsoid.

that the second photon arrives within the life time of the virtual state. In the case of two-photon absorption, the electron transition is induced by two photons, each with half of the required energy of the gap between the two energy levels. This condition can be easily fulfilled when ultrashort light pulse lasers (usually 100 fs or less) are used. The laser beam is tightly focused with a high numerical aperture objective lens into a volume of a photocurable resin creating the highest photon densities within the vicinity of the focus. Since the two-photon absorption rate has a quadratic dependence on the photon density profile, the integrated photosensitive material response is greatly enhanced at the focal spot. The two-photon absorption crosssection is generally extremely low, thus a very high spatial resolution beneath the limit of diffraction of the light used in the direct laser polymerization process can be realised. When focusing a high intensity laser beam tightly into the volume of a liquid- or gel-state photoresin which is transparent to visible or near infrared light, radiation is absorbed by the photoinitiator molecules which generate free radicals (initiation). The radicals 
react with monomers producing monomer-radicals, so the monomer-radicals expand in a chain reaction (chain-propagation) until two radicals meet (termination). The irreversible photopolymerization reaction efficiency is proportional to a multiphoton absorption rate and occurs only in the region where light intensity is above the threshold required for polymerization $I>I_{\text {th }}$.

$$
\begin{aligned}
& d=w_{0} \sqrt{2 \frac{1}{N} \ln \left(\frac{I}{I_{\text {th }}}\right)}, \\
& l=2 z_{\mathrm{R}} \sqrt{\left(\frac{I}{I_{\text {th }}}\right)^{\frac{1}{N}}-1,}
\end{aligned}
$$

where $d$ and $l$ are voxel diameter and length, $w_{0}$ is beam waist at the focal position, $z_{\mathrm{R}}$ is Rayleigh range, $N$ is the order of absorption nonlinearity. A volumetric pixel (voxel) is considered to be the smallest repeating element which adds up to make a threedimensional structure. On the focal spot, initial voxels take the shape of the intensity distribution of the focused laser beam. Voxel growth follows prolonged exposure in all directions uniformly and becomes especially enlarged along intensity distribution with increase in the applied laser power. Voxel expansion is a radical diffusion-dependent process. The effect of variation of power and exposure time on the growth of voxels to formulate the scaling laws for voxels has been studied in detail [87]. Although the final dimensions of the photomodified region depend on the spatial light intensity profile, material response, total exposure dose, photoinitiator concentration and pulse repetition rate have to be taken into account, especially at the close-to-threshold conditions:

$$
\begin{aligned}
& d=\frac{\lambda}{N A} \sqrt{\ln \frac{I_{0}^{N} t \beta \tau v}{I_{\mathrm{th}}}}, \\
& l=\frac{2 z_{\mathrm{R}}}{n} \sqrt{\exp \left[\frac{1}{2}\left(\frac{d N A}{\pi}\right)^{2}\right]-1,}
\end{aligned}
$$

where $\tau$ is exposure time, $\beta$ is experimentally derived constant (two-photon absorption crosssection, concentration and quantum efficiencyof the photoinitiator), $\tau$ and $v$ are laser pulse duration and repetition rate, $n$ is a refractive index of photosensitive material. Theoretically calculated and experimentally measured resolutions (voxel sizes) are graphed in Fig. 3. It is evidently seen that achievable structuring resolution (as well as the aspect ratio of the voxel) greatly depends on the properties of the material.
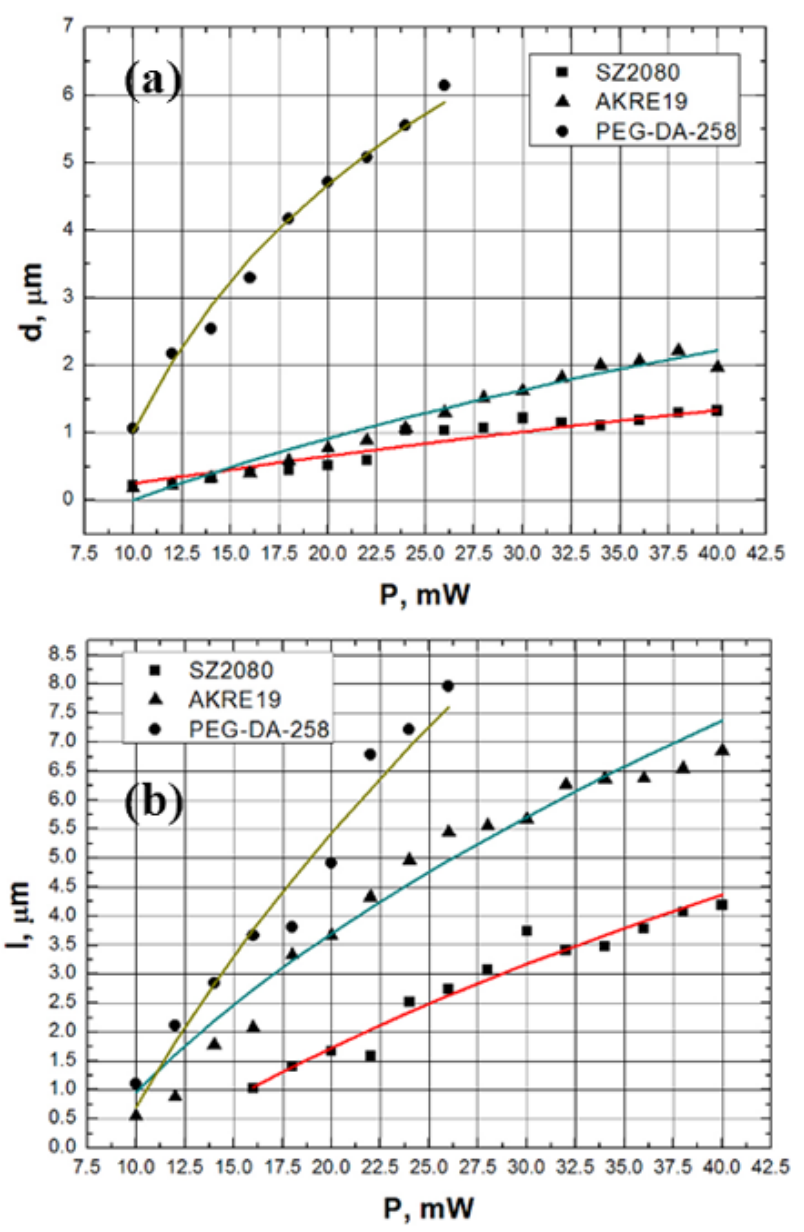

Fig. 3. Direct laser polymerization structuring spatial resolution graphs. Voxel diameter $d$ (a) and length $l$ (b) versus applied laser power $P$ in different used photopolymers.

\section{Examples of functional micro-/nano-devices}

The field of applications has expanded dramatically since the first experimental demonstrations of the principle itself to the nowadays micro/nanostructuring via direct laser polymerization. The capability of this technique to create complex three-dimensional structures with resolution, reproducibility and throughput superior to other approaches has established this young technology as seriously mature 


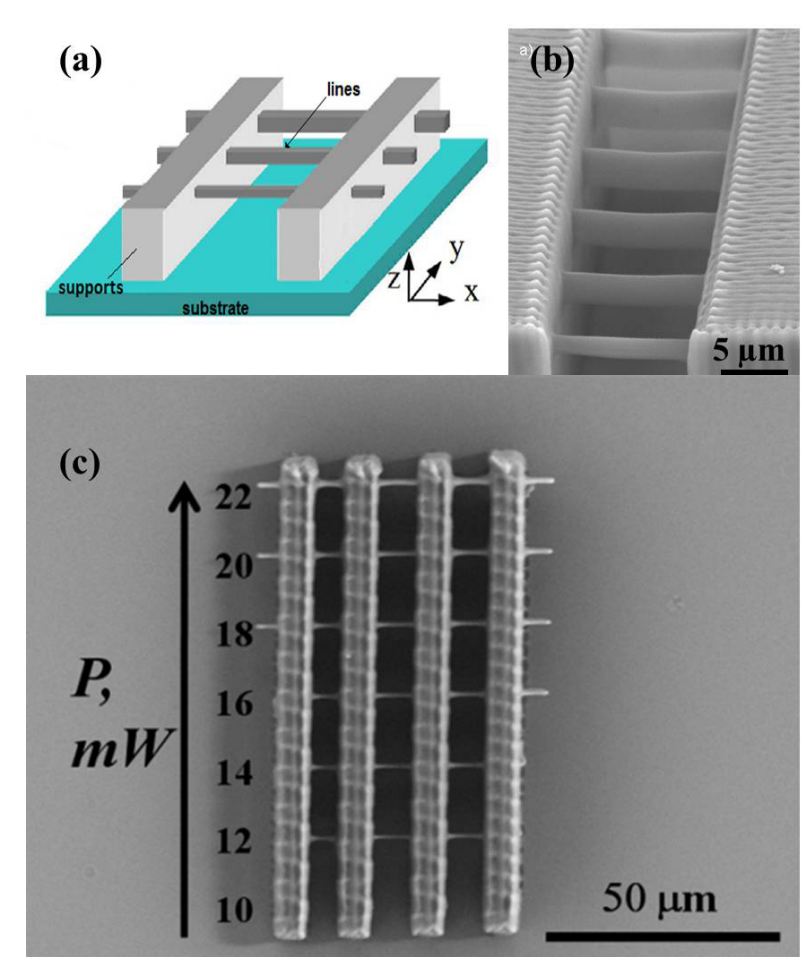

Fig. 4. Resolution bridge for power scaling measurements: (a) schematic of a resolution bridge consisting of supports fabricated on the substrate and suspended lines hanging in between them; SEM images of (b) oblique and (c) top views. It is seen that line thickness and height increase as the applied laser power and is increased.

and unique. An interest in direct laser polymerization has been continuously growing from both sides, fundamental and technological, and there is still a lot of room for improvement of both.

Next, sample structures proving the feasibility of the technique for the fabrication of various functional structures will be presented. In all cases an immersion oil $N A=1.4100 \times$ objective and frequency doubled $515 \mathrm{~nm}$ irradiation wavelength (except for woodpile structures it was kept fundamental of $1030 \mathrm{~nm}$ ) was used (pulse duration was set at $300 \mathrm{fs}$ and repetition rate at $200 \mathrm{kHz}$ ). The 3 DPoli software was used for the complete control and automation of the direct laser polymerization set-up [88].

\subsection{Three-dimensional periodic structures as woodpile templates}

In this section we show successfully fabricated three-dimensional templates having woodpile geometry. Such kind of structures can find numer- ous applications in high and low refractive index contrast photonic templates [42, 89], microfluidic or cell scaffolding applications [90, 91]. It is worth mentioning that such structures can serve as masks for host material filling techniques; direct patterning of $\mathrm{TiO}_{2}$ and infiltration of $\mathrm{Si}$ was already demonstrated [92, 93]. It dramatically expands the usage of such three-dimensional structures for the creation of functional micro-/nano-devices with desired optical, electric or mechanical properties.

The woodpile structures were fabricated to have a varying filling factor. It was achieved by increasing the lateral period $p_{x y}$ from 0.4 to $2.3 \mu \mathrm{m}$ and keeping the same irradiation power $P$ at $1.78 \mathrm{~mW}$ or setting $p_{x y}$ at $2 \mu \mathrm{m}$ and reducing $P$ from 1.8 to $1.3 \mathrm{~mW}$. The structures were fabricated from a hybrid zirconium-doped polymer SZ2080 photosensitized by 4,4'-bis(diethylamino) benzophenone. Some samples were prepared from a hybrid polymer doped heavier with zirconium SZ3070 and mixed with amine groups from DMAEMA (2-(dimethylamino)ethyl methacrylate) [94]. Woodpiles were of 4-5 unit cell height, which corresponds to 16-20 layers. Figure 5 shows SEM images of an array of woodpiles fabricated out of SZ2080 when irradiation power was reduced from left to right. With lower power thinner lines are fabricated (Fig. $5(b-d))$, and while keeping the same lateral period the filling factor is finely reduced. Figure $5(e, f)$ shows a $45^{\circ}$ angle view of a woodpile in column I where a longitudinal period is observed.

\subsection{Nanogratings}

Electron beam lithography is traditionally considered to be the structuring technique distinguished for the highest spatial resolution. Electrons of high energy can excite even non-photosensitized materials and by tuning their acceleration velocity one can tune the penetration (material modification) depth. However, next to its advantages lie a few limitations keeping the electron beam lithography at a distance from practical usage in industry. Among them is a high cost of equipment, requirement of clean room facilities as well as relatively low fabrication throughput and restricted structuring in three dimensions (even no high aspect ratio in two dimensions can be achieved).

In this section we show a possibility to reach ultrahigh resolution of two-dimensional phase grating 


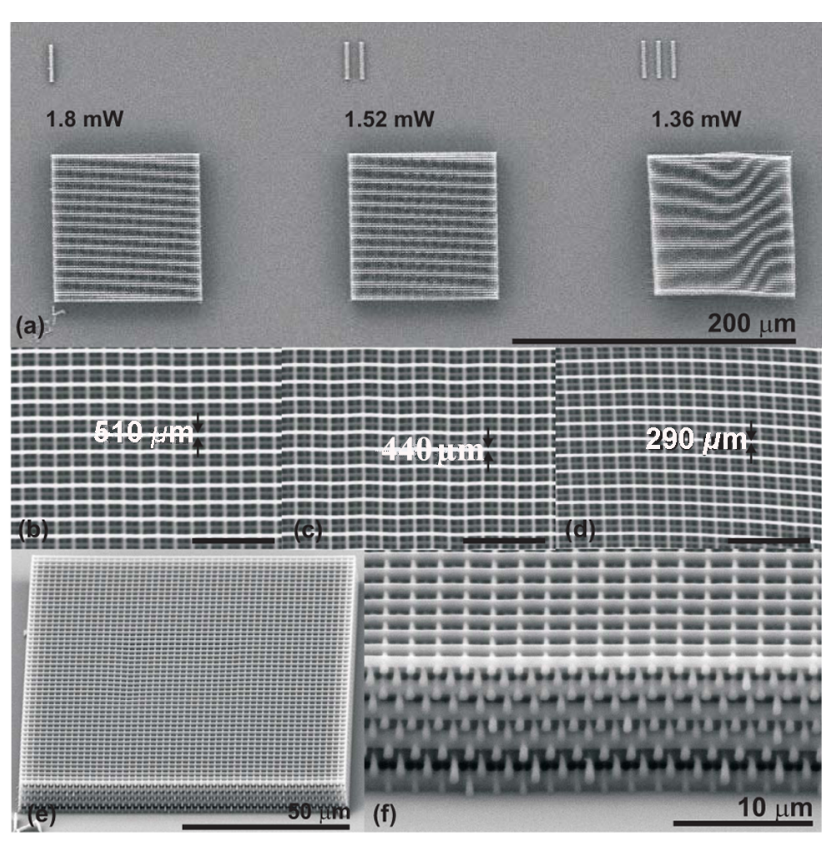

Fig. 5. All woodpiles have designed measurements $100 \times 100 \times 20 \mu \mathrm{m}^{3}$ and lateral period $p_{x y}$ of $2 \mu \mathrm{m}$. Different irradiation power was used to fabricate the structures which resulted in varying feature line thickness. A woodpile in column I was fabricated using $1.8 \mathrm{~mW}$ irradiation power, in column II $1.52 \mathrm{~mW}$, in column III $1.36 \mathrm{~mW}$. Respective feature line thickness is shown in (b-d). $45^{\circ}$ angle view of the woodpile in column I demonstrating the longitudinal period is shown in (e) and (f).

by employing conventional laser micro/nanofabrication set-up. The produced nanogratings were obtained using the following strategy.

Two-dimensional gratings with a period of $400 \mathrm{~nm}$ were fabricated out of a hybrid polymer with added amine groups and photosensitized with thioxanthen-9-one. In order to achieve the desired resolution, irradiation power which was just enough to produce stable gratings that withstand development was set and then the scanning plane of a laser beam was translated deeper into substrate in steps of $250 \mathrm{~nm}$. This approach is shown in Fig. 6(a), where the dashed blue line indicates the surface line of a produced grating in each case of laser beam focusing. Figures 6(b, c) show SEM images of 2D gratings that have a period of $400 \mathrm{~nm}$.

As in all lithography techniques, the manufactured patterns can be transferred to other materials or substrates as well as sputtered with metal or semiconductor thin layers or removed applying lift-off method [95].

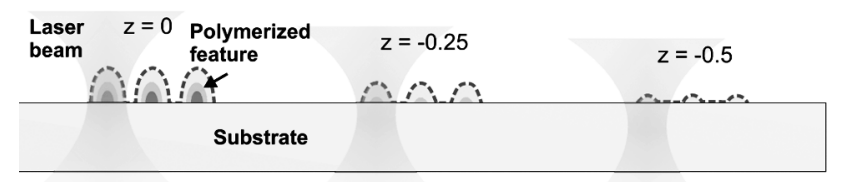

a)

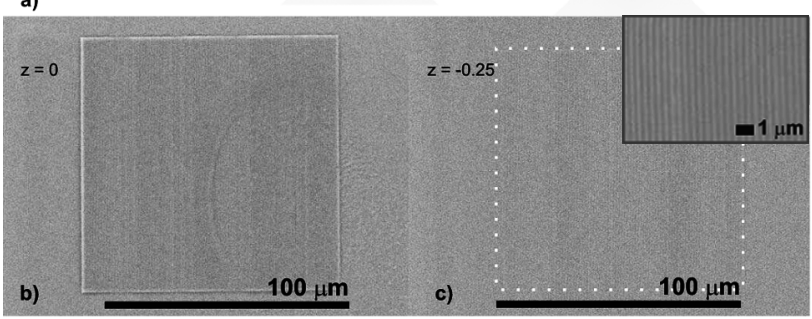

Fig. 6. (a) The scheme of $2 \mathrm{D}$ gratings of $400 \mathrm{~nm}$ fabrication. Laser beam focus plane was translated into the substrate by $250 \mathrm{~nm}$ and the resulting grating with distinct separation between neighbouring features was produced $(b, c)$.

\subsection{Opto-fluidics}

Direct laser polymerization is an attractive approach for structuring micro-optical devices due to several reasons:

(i) material properties with a tunable optical refractive index (which can be matching the substrate or not) [96, 97];

(ii) true free-form fabrication and flexible change of the shape [98, 99];

(iii) easy integration [100, 101]; and

(iv) material can be additionally functionalized by doping with fluorescent dyes [102].

Lab-on-chip [103] is an interesting device conception which should be a cheap and disposable chip to be used for various tests replacing expensive today's laboratory equipment. Before it becomes widely available several important challenges must be overcome. One of these challenges is to create accurate, simple and cheap sensors. Several possible sensor conceptions were suggested [104, 105] although they are not really suitable for widespread usage because of their complexity, difficult fabrication processes, and so on. A solution to overcome such a problem might be a usage of an opto-fluidic sensor with a specifically designed microlens array as its main component (Fig. 7 (a)). A microlens array would be fabricated directly to a micro-fluidic channel (Fig. $\nabla(b)$ ). Above these microlenses would be a light detector. Every lens would be calculated to focus light to a detector in different refractive indices thus making only one lens focus light correctly to a detector at any 
given time. In this way, it would be possible to determine which lens focuses light best and, using that data, to extract the refractive index of the medium in a microchannel. There would be no problems to fabricate structures like these because of easy integration offered by a direct laser writing technique 100,101 .

In this work a Ti:Sapphire oscillator system Tsunami with pulse duration of $80 \mathrm{fs}$, repetition rate of $80 \mathrm{MHz}$ and wavelength of $800 \mathrm{~nm}$ was used. Structures were fabricated out of a hybrid organic-inorganic SZ2080 polymer photosensitized by adding 2 wt.\% of 4,4'-bis(diethylamino) benzophenone. After fabrication the structures were developed in methyl isobutyl ketone. Both

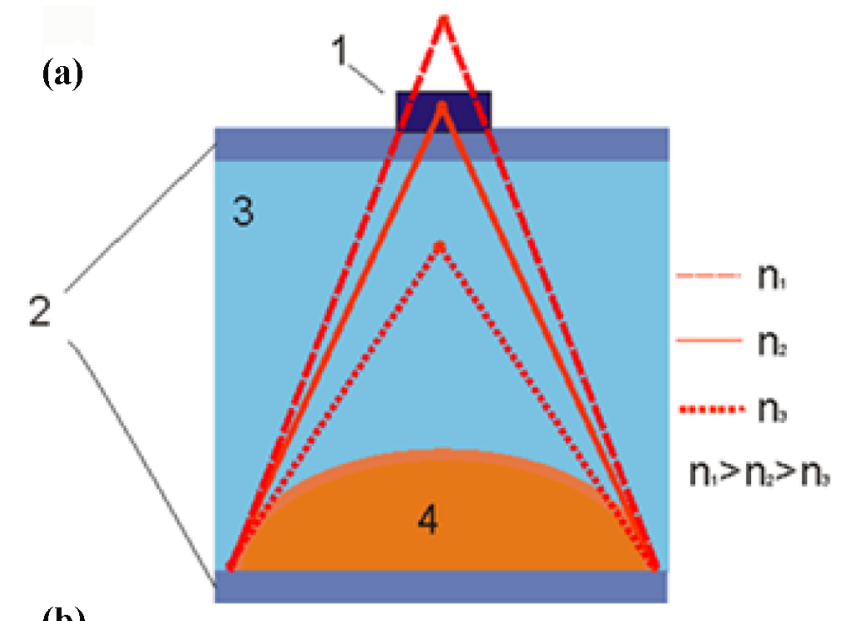

(b)

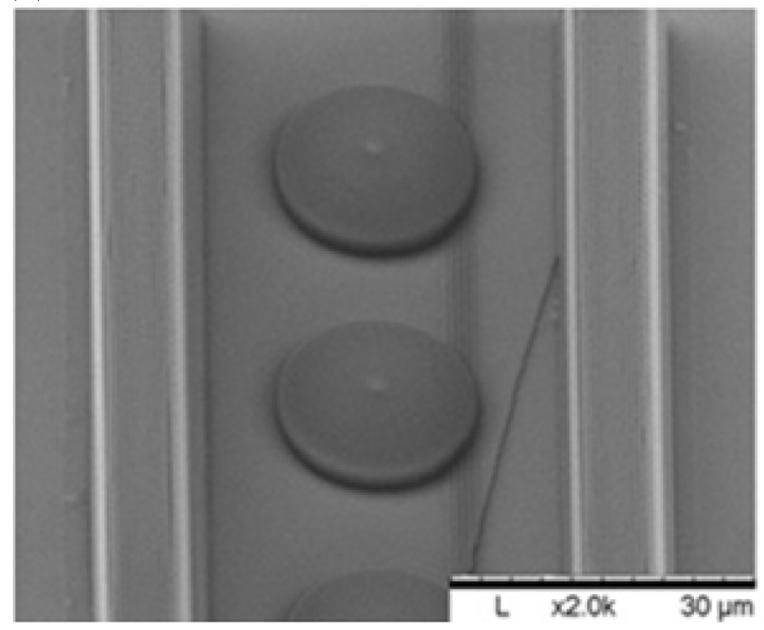

Fig. 7. (a) Components of an opto-fluidic sensor using a microlens as its main component: (1) detector, (2) micro-fluidic channel, (3) surrounding medium, (4) microlens; $n_{1}, n_{2}, n_{3}$ refractive indices of medium in microchannel. (b) SEM image of microlenses integrated directly into a micro-fluidic channel. spherical and a spherical microlenses were modeled and fabricated during this work. It was achived because of a true free-form fabrication possibility [98, 99] that the direct laser technique offers. The diameter of lenses with spherical symmetry was $60 \mu \mathrm{m}$ and the radius of curvature of the lens surface was $54.5 \mu \mathrm{m}$. Aspherical lenses were $50 \mu \mathrm{m}$ in diameter. During the fabrication process the sample translation velocity was kept at $200 \mu \mathrm{m} / \mathrm{s}$, optical laser power at $25 \mathrm{~mW}$. The fabrication time of a single lens with diameters from 50 to $60 \mu \mathrm{m}$ was from $45 \mathrm{~min}$ to $1 \mathrm{~h}$, if all inner volume of the lens was fabricated using direct laser writing. The fabrication time was improved by applying a method in which only the outer shell of a microlens was fabricated (Fig. 8(a)). In this case, microlenses of the same diameter could be fabricated in only 4-5 minutes using a laser and additional 3 minutes of UV exposure. Further improvement in fabrication efficiency was done by applying the PDMS soft-lithography [106] technique. This technique allows replication of an entire microlens array by using a rapid and simple approach. It also allows replicating microlenses in polymers that might be impractical to use in direct laser writing (Fig. 8(b)). Masks for soft-lithography were fabricated from poly(dimethylsiloxane) (PDMS) elastomer. PDMS was also used for replicas. Another material used for replicas was PEG-DA-258 (poly(ethylen)glycol diacrylate of M.w: = 258). PEG-DA-258 was photosensitized by adding 2 wt.\% of Irgacure 369. Apply- (a)

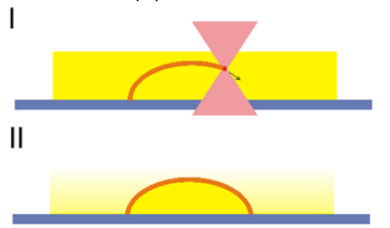

III

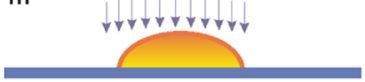

IV

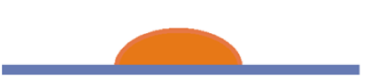

(b)

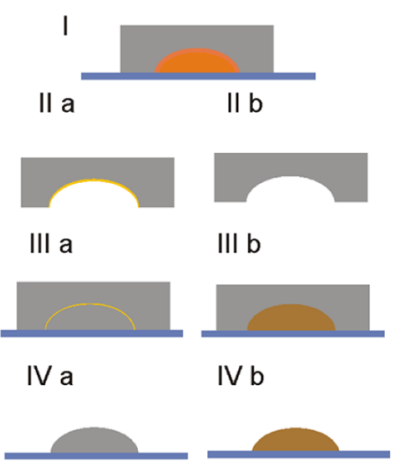

Fig. 8. (a): I Outer shell fabrication, II development, III UV light exposure, IV produced lens. (b): I PDMS on the original microlens, IIa mask covered with $15 \mathrm{~nm}$ of gold, IIb mask, IIIa making of PDMS replica, IIIb making of PEGDA-258 replica, IVa PDMS replica, IVb PEGDA-258 replica. 
ing deadhesion layer of $15 \mathrm{~nm}$ gold one can make a replica into the same material, for instance transfer PDMS into PDMS.

During this work, microlenses for usage in optofluidical sensors were modelled and fabricated using the direct laser writing technique. The method of fabricating only the outer shell was applied. Microlens arrays were also replicated using PDMS based soft-lithography. Profiles of replicated lenses were really close to the profile of the original microlens (Fig. 9). Also, microlens focusing properties in different liquids were tested. The tests were successful - microlenses showed significant focal distance changes (up to tens of micrometres) in liquids with a relatively small difference in their refractive index (order of 0.01). Although these results were promising, some problems associated with the focusing of these lenses, such as spherical and chromatic aberrations, were noticed. Work should be continued using solely aspherical lenses and improved methods for focal length measurement.

\subsection{Three-dimensional electric circuits}

Direct laser polymerization enables fabrication of three-dimensional microstructures on opaque and reflective surfaces [107]. Furthermore, the usage of materials having metal binding groups which can be subsequently metalized and gain ohmic conductivity by applying wet chemistry methods has already been demonstrated [94]. To show the proof of the principle a three-dimensional microstructure consisting of 2 micro-electrodes and several nano-wires was manufactured on a gold layer of $20 \mathrm{~nm}$. This was

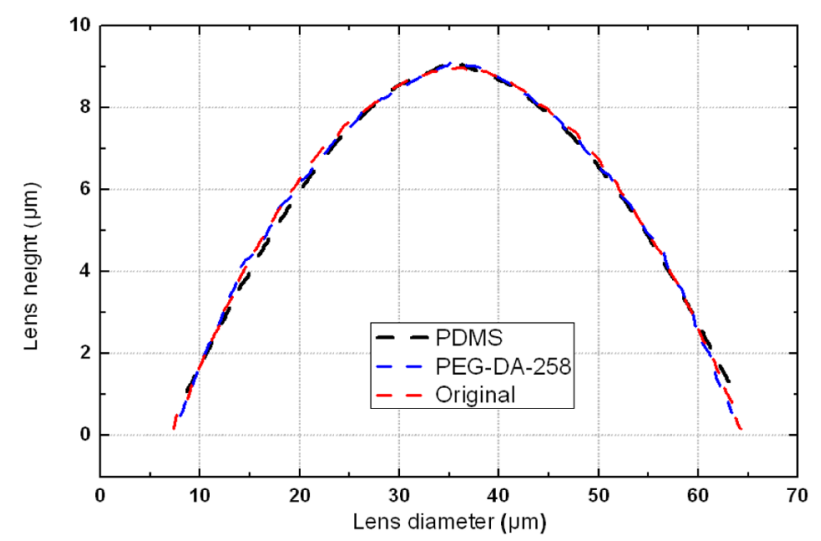

Fig. 9. Comparison of the microlenses replicated in PEG-DA-258 (blue online) and PDMS (black online), the profile of the original microlens (red online). done by initially sputtering the gold layer (gold sputterer Quorum QR 150 RS) on a cover glass. Then it was treated as a substrate and standard direct laser polymerization was performed. A hybrid polymer doped with zirconium SZ3070 and mixed with 30\% DMAEMA (2-(dimethylamino)ethyl methacrylate) which has metal binding groups was used for structure fabrication. The resulting structure is depicted in Fig. 10. The nanowires are suspended $15 \mu \mathrm{m}$ above the electroconductive gold surface.

This approach presents a novel way to create integrated three-dimensional electric circuits (3D-IC) which can have advantages to planar ones, as it allows to increase the density of interconnects compacting them into the third dimension. Thus, compared to the established printed electronics, more sophisticated architectures can be realized; they can have advantages in sensor devices or simply help in avoiding heat excess. Additionally, it can be employed for the MOEMS technology where several electric micro-devices need to be interconnected.

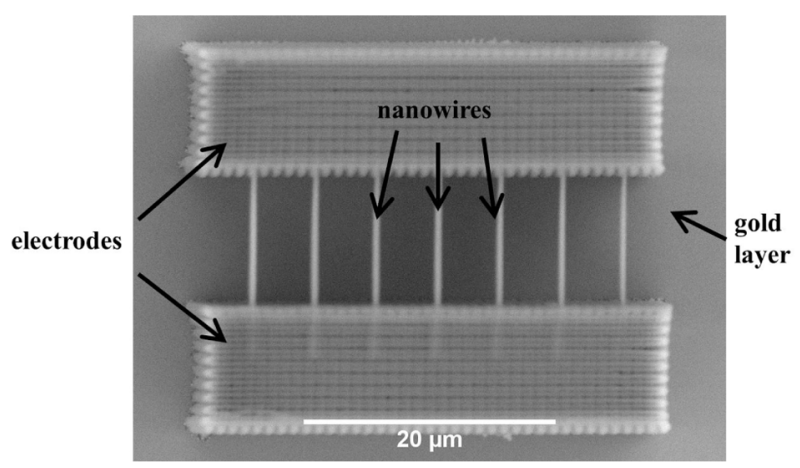

Fig. 10. Three-dimensional structure consisting of 2 micro-electrodes and 7 nano-wires. The nano-wires are suspended in $15 \mu \mathrm{m}$ above the electroconductive gold surface.

\section{Summary}

In brief, the principle of direct laser polymerization employing ultrafast lasers was introduced as well as its vast potential for applications in photonics, micro-optics and nano-electronics was demonstrated experimentally. The presented technique was compared to alternative already well-established techniques for micro/nanostructuring of planar and 
three-dimensional objects. Its efficiency, scalability and the variety of processable materials as well as flexible integration makes it advantageous among other techniques. The peculiarities of pulse duration, sample translation trajectory and the influence of the material on the final object shape were discussed. Sample nanophotonic, opto-fluidic and integrated circuit functional structures were introduced.

\subsection{Outlook}

The employment of high repetition rate amplified femtosecond pulses combined with fast sample translation and precise beam deflection subsystems seems to be an efficient way for precise energy delivery in three-dimensional micro/nanostructuring at macro volumes. If additional beam shaping techniques are used [108], it can reach the final manufactured structure range (of up to $\mathrm{cm}^{3}$ ), yet still keeping its intrinsic geometry and $\sim 100 \mathrm{~nm}$ fidelity. So, it is strongly believed that it can find applications for the creation of artificial scaffolds out of biopolymers for stem cell studies [109] and tissue engineering [110] in the near future.

\section{Acknowledgements}

This research was funded by a Biomatrix grant (No. 31V-39/2012) from the Agency for Science, Innovation and Technology, Lithuania.

\section{References}

[1] S. Maruo, O. Nakamura, and S. Kawata, Threedimensional microfabrication with two-photonabsorbed photopolymerization, Opt. Lett. 2(22), 132-134 (1997).

[2] M. Miwa, S. Juodkazis, T. Kawakami, S. Matsuo, and H. Misawa, Femtosecond two-photon stereolithography, Appl. Phys. A 73, 561-566 (2001).

[3] C. LaFratta, J. Fourkas, T. Baldacchini, and R. Farrer, Multiphoton fabrication, Angew. Chem. Int. Ed. 46, 6238-6258 (2007).

[4] M. Farsari and B. Chichkov, Materials processing: Two-photon fabrication, Nat. Photon. 3, 450-452 (2009).

[5] G. von Freymann, Direct laser writing, Nat. Photon. 4, 22-23 (2010).

[6] S. Juodkazis, V. Mizeikis, K. Seet, M. Miwa, and H. Misawa, Two-photon lithography of nanorods in SU-8 photoresist, Nanotechnology 16, 846-849 (2005).
[7] F. Qi, Y. Li, D. Tan, H. Yang, and Q. Gong, Polymerized nanotips via two-photon photopolymerization, Opt. Express 15(3), 971-976 (2007).

[8] S. Park, T. Lim, D.-Y. Yang, N. Cho, and K.-S. Lee, Fabrication of a bunch of sub-30-nm nanofibers inside microchannels using photopolymerization via a long exposure technique, Appl. Phys. Lett. 89(17), 173133 (2006).

[9] D. Tan, Y. Li, F. Qi, H. Yang, Q. Gong, X. Dong, and $\mathrm{X}$. Duan, Reduction in feature size of twophoton polymerization using SCR-500, Appl. Phys. Lett. 90(7), 071106 (2007).

[10]M. Malinauskas, G. Bičkauskaitè, M. Rutkauskas, D. Paipulas, V. Purlys, and R. Gadonas, Selfpolymerization of nano-fibres and nano-membranes induced by two-photon absorption, Lith. J. Phys. 50(1), 135-140 (2010).

[11]T. Baldacchini, C. LaFratta, R. Farrer, M. Teich, B. Saleh, M. Naughton, and J. Fourkas, Acrylicbased resin with favorable properties for threedimensional two-photon polymerization, J. Appl. Phys. 95, 6072-6076 (2004).

[12] T. Kondo, S. Juodkazis, V. Mizeikis, and H. Misawa, Three-dimensional high-aspect-ratio recording in resist, J. Non-Cryst. Solids 354(12-13), 2010 (2008).

[13] L. Nguyen, M. Straub, and M. Gu, Acrylate-based photopolymer for two-photon microfabrication and photonic applications, Adv. Funct. Mater. 15(2), 209-216 (2005).

[14]J. Stampfl, S. Baudis, C. Heller, R. Liska, A. Neumeister, R. Kling, A. Ostendorf, and M. Spitzbart, Photopolymers with tunable mechanical properties processed by laser-based high-resolution stereolithography, J. Micromech. Microeng. 18, 1-9 (2008).

[15]J. Serbin, A. Egbert, A. Ostendorf, B. Chichkov, R. Houbertz, G. Domann, J. Schulz, C. Cronauer, L. Frohlich, and M. Popall, Femtosecond laser-induced two-photon polymerization of inorganic-organic hybrid materials for applications in photonics, Opt. Lett. 28(5), 301-303 (2003).

[16] T. Tanaka, Plasmonic metamaterials produced by two-photon-induced photoreduction technique, J. Laser Micro/Nanoeng. 3(3), 152-156 (2008).

[17] J. Halimeh, T. Ergin, J. Mueller, N. Stenger, and $\mathrm{M}$. Wegener, Photorealistic images of carpet cloaks, Opt. Express 17(22), 19328-19336 (2009).

[18]T. Ergin, N. Stenger, P. Brenner, J. Pendry, and M. Wegener, Three-dimensional invisibility cloak at optical wavelengths, Science 328(5976), 337339 (2010).

[19]K. Muamer, D. Guillaume, T.-M. Chang, S. Guenneau, and S. Enoch, Phys. Opt., (2011). http://arxiv.org/abs/1102.0900v1 
[20]A. Ovsianikov, S. Schlie, A. Ngezahayo, A. Haverich, and B. Chichkov, Two-photon polymerization technique for microfabrication of CAD-designed 3D scaffolds from commercially available photosensitive materials, J. Tissue Eng. Regen. Med. 1, 443-449 (2007).

[21]C. Heller, M. Schwentenwein, G. Russmueller, F. Varga, J. Stampfl, and R. Liska, Vinyl esters: Low cytotoxicity monomers for the fabrication of biocompatible $3 \mathrm{~d}$ scaffolds by lithography based additive manufacturing, J. Polymer. Sci. A Polymer. Chem. 47(24), 6941-6954 (2009).

[22] F. Claeyssens, E.A. Hasan, A. Gaidukeviciute, D.S. Achilleos, A. Ranella, C. Reinhardt, A. Ovsianikov, X. Shizhou, C. Fotakis, M. Vamvakaki, B.N. Chichkov, and M. Farsari, Three-dimensional biodegradable structures fabricated by two-photon polymerization, Langmuir 25(5), 3219-3223 (2009).

[23] D. Psaltis, S. Quake, and C. Yang, Developing optofluidic technology through the fusion of microfluidics and optics, Nature 442, 381-386 (2006).

[24] D. Janasek, J. Franzke, and A. Manz, Scaling and the design of miniaturized chemical-analysis systems, Nature 442, 374-380 (2006).

[25] S. Boutami, B. Bem Bakir, J.-L. Leclercq, X. Letartre, P. Rojo-Romeo, M. Garrigues, P. Viktorovitch, I. Sagnes, L. Legratiet, and M. Strassner, Highly selective and compact tunable MOEMS photonic crystal Fabry-Perot filter, Opt. Express 14(8), 3129-3137 (2006).

[26] S. Bargiel, K. Rabenorosoa, C. Clévy, C. Gorecki, and P. Lutz, Towards micro-assembly of hybrid MOEMS components on a reconfigurable silicon free-space micro-optical bench, J. Micromech. Microeng. 20(4), 045012 (2010).

[27]H.-B. Sun, S. Matsuo, and H. Misawa, Threedimensional photonic crystal structures achieved with two-photon-absorption photopolymerization of resin, Appl. Phys. Lett. 74, 786-788 (1999).

[28] R. Borisov, G. Dorojkina, N. Koroteev, V. Kozenkov, S. Magnitskii, D. Malakhov, A. Tarasishin, and A. Zheltikov, Femtosecond two-photon photopolymerization: a method to fabricate optical photonic crystals with controllable parameters, Laser Phys. 8(5), 1105-1105 (1998).

[29] C. Reinhardt, R. Kiyan, S. Passinger, A. Stepanov, A. Ostendorf, and B. Chichkov, Rapid laser prototyping of plasmonic components, Appl. Phys. A 89, 321-325 (2007).

[30] A. Seidel, C. Ohrt, S. Passinger, C. Reinhardt, R. Kiyan, and B. Chichkov, Nanoimprinting of dielectric loaded surface-plasmon-polariton waveguides using masters fabricated by 2 -photon polymerization technique, J. Opt. Soc. Am. B 26(4), 810-812 (2009).

[31]M. Rill, C. Plet, M. Thiel, I. Staude, G. von Freymann, S. Linden, and M. Wegener,
Photonic metamaterials by direct laser writing and silver chemical vapor deposition, Nat. Mater. 7(7), 543-546 (2008).

[32] P. Naulleau, C. Anderson, J. Chiu, P. Denham, S. George, K. Goldberg, M. Goldstein, B. Hoef, R. Hudyma, G. Jones, C. Koh, B. L. Fontaine, A. Ma, W. Montgomery, D. Niakoula, J. Park, T. Wallow, and S. Wurm, 22-nm half-pitch extreme ultraviolet node development at the SEMATECH Berkeley microfield exposure tool, Microelectron. Eng. 86(4-6), 448-455 (2009).

[33] G. Sunne, Electron beam lithography for nanofabrication, PhD Thesis (University of Barcelona, Barcelona, 2008).

[34]E. Di Fabrizio, R. Fillipo, S. Cabrini, R. Kumar, F. Perennes, M. Altissimo, L. Businaro, D. Cojac, L. Vaccari, M. Prasciolu, and P. Candeloro, X-ray lithography for micro- and nano-fabrication at ELETTRA for interdisciplinary applications, J. Phys. Condens. Matter 16(33), 3517-3535 (2004).

[35] H. Schift, Nanoimprint lithography: An old story in modern times? A review, J. Vac. Sci. Technol. B 26(2), 458-480 (2008).

[36] M. Walther, A. Ortner, H. Meier, U. Löffelmann, P.J. Smith, and J.G. Korvink, Terahertz metamaterials fabricated by inkjet printing, Appl. Phys. Lett. 95(25), 251107 (2009).

[37]T. Boland, X. Tao, B. Damon, B. Manley, P. Kesari, S. Jalota, and S. Bhaduri, Drop-on-demand printing of cells and materials for designer tissue constructs, Mater. Sci. Eng. C 27(3), 372-376 (2007).

[38] H. Benkreira and M. I. Khan, Air entrainment in dip coating under reduced air pressures, Chem. Eng. Sci. 63(2), 448-459 (2008).

[39] K. Tan, C. Chua, K. Leong, C. Cheah, P. Cheang, M.A. Bakar, and S. W. Cha, Scaffold development using selective laser sintering of polyetheretherketone-hydroxyapatite biocomposite blends, Biomaterials 24(18), 3115-3123 (2003).

[40] A. Simchi, F. Petzoldt, and H. Pohl, On the development of direct metal laser sintering for rapid tooling, J. Mater. Process. Technol. 141, 319-328 (2003).

[41] V. Mizeikis, K.K. Seet, S. Juodkazis, and H. Misawa, Three-dimensional woodpile photonic crystal crystal templates for the infrared spectral range, Opt. Lett. 29(17), 2061-2063 (2004).

[42] M. Deubel, G.V. Freymann, M. Wegener, S. Pereira, K. Busch, and C. Soukoulis, Direct laser writing of three-dimensional photonic-crystal templates for telecommunications, Nature Mater. 3, 444-447 (2004).

[43]J. Serbin, A. Ovsianikov, and B. Chichkov, Fabrication of woodpile structures by multi-photon polymerization and investigation of their optical properties, Opt. Express 12, 5221-5228 (2004). 
[44] R. Guo, S. Xiao, X. Zhai, J. Li, A. Xia, and W. Huang, Micro lens fabrication by means of femtosecond two photon photopolymerization, Opt. Express 14(2), 810-816 (2006).

[45]M. Malinauskas, H. Gilbergs, A. Žukauskas, V. Purlys, D. Paipulas, and R. Gadonas, A femtosecond laser-induced two-photon photopolymerization technique for structuring microlenses, J. Opt. 12(3), 035204 (2010).

[46] S. Maruo, A. Takaura, and Y. Saito, Optically driven micropump with a twin spiral microrotor, Opt. Express 17, 18525-18532 (2009).

[47] D. Wu, Q. Chen, L. Niu, J. Wang, J. Wang, R. Wang, H. Xia, and H. Sun, Femtosecond laser rapid prototyping of nanoshells and suspending components towards microfluidic devices, Lab Chip 9(16), 2391-2394 (2009).

[48] R. Narayan, C. Jin, A. Doraiswamy, I. Mihailescu, M. Jelinek, A. Ovsianikov, B. Chichkov, and D. Chrisey, Laser processing of advanced bioceramics, Adv. Eng. Mater. 7(12), 1083-1098 (2005).

[49] A. Ovsianikov, B. Chichkov, and R. J. Narayan, Rapid prototyping of ossicular replacement prostheses, Appl. Surf. Sci. 253(15), 6603-6607 (2007).

[50] Y. Ha, J. Choi, and S. H. Lee, Mass production of 3-D microstructures using projection microstereolithography, J. Mech. Sci. Technol. 22(3), 51545261 (2008).

[51]I. Park, Y. Ha, and S. Lee, Cross-section segmentation for improving the shape accuracy of microstructure array in projection microstereolithography, Int. J. Adv. Manuf. Technol. 46, 151-161 (2010).

[52] D. Yang, S. Park, T. Lim, H.-J. Kong, S. Yi, H. Yang, and K.-S. Lee, Ultraprecise microreproduction of a three-dimensional artistic sculpture by multipath scanning method in two-photon photopolymerization, Appl. Phys. Lett. 90, 013113 (2007).

[53]M. Malinauskas, H. Gilbergs, V. Purlys, A. Žukauskas, M. Rutkauskas, and R. Gadonas, Femtosecond laser-induced multi-photon photopolymerization for structuring of micro-optical and photonic devices, Proc. SPIE 7366, 736622 (2009).

[54] K. Gonsalves, L. Merhari, H. Wu, and Y. Hu, Organic-inorganic nanocomposites: Unique resists for nanolithography, Adv. Mater. 13(10), 703714 (2001).

[55]I. Sakellari, A. Gaidukeviciute, A. Giakoumaki, D. Gray, C. Fotakis, M. Farsari, M. Vamvakaki, C. Reinhardt, A. Ovsianikov, and B. Chichkov, Two-photon polymerization of titanium sol-gel containing composites for three-dimensional structure fabrication, Appl. Phys. A 100, 359-364 (2010).

[56] T. Tanaka, A. Ishikawa, and S. Kawata, Twophoton-induced reduction of metal ions for fabricating three-dimensional electrically conduc- tive metallic microstructure, Appl. Phys. Lett. 88, 081107 (2006).

[57] V. Mizeikis, S. Juodkazis, R. Tarozaitè, J. Juodkazyte், K. Juodkazis, and H. Misawa, Fabrication and properties of metalo-dielectric photonic crystal structures for infrared spectral region, Opt. Express 15, 8454-8464 (2007).

[58]M. Rill, C. Plet, M. Thiel, I. Staude, G. von Freymann, S. Linden, and M. Wegener, Photonic metamaterials by direct laser writing and silver chemical vapour deposition, Nat. Mater. 7, 543-546 (2008).

[59] L. Vurth, P. Baldeck, O. Stephan, and G. Vitrant, Two-photon induced fabrication of gold microstructures in polystyrene sulfonate thin films using a ruthenium(ii) dye as photoinitiator, Appl. Phys. Lett. 92(17), 171103 (2008).

[60] S. Park, T. Lim, D. Yang, R. Kim, and K. Lee, Improvement of spatial resolution in nanostereolithography using radical quencher, Macromol. Res. 14(5), 559-564 (2006).

[61] W. Haske, V. Chen, J. Hales, W. Dong, S. Barlow, S. Marder, and J. Perry, $65 \mathrm{~nm}$ feature sizes using visible wavelength 3 -D multiphoton lithography, Opt. Express 15, 3426-3436 (2007).

[62]X. Dong, Z. Zhao, and X. Duan, Improving spatial resolution and reducing aspect ratio in multiphoton polymerization nanofabrication, Appl. Phys. Lett. 92, 091113 (2008).

[63] http://www.nanoscribe.de/

[64] http://www.lzh.de/

[65] http://www.newport.com/

[66] http://www.teemphotonics.com/

[67] S. Passinger, A. Ovsianikov, R. Kiyan, C. Reinhardt, A. Ostendorf, and B.N. Chichkov, Two-photon polymerization for industrial aplications, in: Procedings of LPM2007 (2007).

[68]M. Malinauskas, V. Purlys, A. Žukauskas, G. Bičkauskaitè, T. Gertus, P. Danilevičius, D. Paipulas, M. Rutkauskas, H. Gilbergs, D. Baltriukiené, L. Bukelskis, R. Širmenis, V. Bukelskienè, R. Gadonas, V. Sirvydis, and A. Piskarskas, Laser two-photon polymerization micro- and nanostructuring over a large area on various substrates, Proc. SPIE 7715, 77151F-1 (2010).

[69] J. Stampfl, R. Inführ, K. Stadlmann, N. Pucher, V. Schmidt, and R. Liska, Materials for the fabrication of optical waveguides with two photon photopolymerization, in: Proc. Fifth International WLT-Conference on Lasers in Manufacturing (2009).

[70] M. Malinauskas, D. Baltriukiene, A. Kraniauskas, P. Danilevicius, R. Jarasiene, R. Sirmenis, A. Zukauskas, E. Balciunas, V. Purlys, R. Gadonas, V. Bukelskiene, V. Sirvydis, and A. Piskarskas, In vitro and in vivo biocompatibility study on laser $3 \mathrm{~d}$ 
microstructurable polymers, Appl. Phys. A 108(3), 751-759 (2012).

[71]A. Ovsianikov, M. Malinauskas, S. Schlie, B. Chichkov, S. Gittard, R. Narayan, M. Löbler, K. Sternberg, K.-P. Schmitz, and A. Haverich, Three-dimensional laser micro- and nanostructuring of acrylated poly(ethylene glycol) materials and evaluation of their cytoxicity for tissue engineering applications, Acta Biomater. 7, 967-974 (2011).

[72]P. Danilevicius, S. Rekstyte, E. Balciunas, A. Kraniauskas, R. Sirmenis, D. Baltriukiene, V. Bukelskiene, R. Gadonas, V. Sirvydis, A. Piskarskas, and M. Malinauskas, Laser 3D micro/nanofabrication of polymers for tissue engineering applications, Opt. Laser Technol. 45, 518524 (2013).

[73]E. Stankevicius, M. Malinauskas, M. Gedvilas, B. Voisiat, and G. Raciukaitis, Fabrication of periodic micro-structures by multi-photon polymerization using the femtosecond laser and four-beam interference, Mat. Sci. 17(3), 244-248 (2011).

[74]B. Mills, D. Kundys, M. Farsari, S. Mailis, and R. W. Eason, Single-pulse multiphoton fabrication of high aspect ratio structures with sub-micron features using vortex beams, Appl. Phys. A 108, 651-655 (2012).

[75]H. Lin, B. Jia, and M. Gu, Dynamic generation of Debye diffraction-limited multifocal arrays for direct laser printing nanofabrication, Opt. Lett. 36(3), 406-408 (2011).

[76]S. Passinger, Two-photon polymerization and the application for surface plasmon polaritons, $\mathrm{PhD}$ Thesis (Leibniz Universitat, Hannover, 2008) pp. $1-126$.

[77] A. Ovsianikov, S. Passinger, R. Houbertz, and B. Chichkov, Three dimensional material processing with femtosecond lasers in: Laser Ablation and Its Applications (2007) pp. 121-157.

[78]M. Malinauskas, A. Žukauskas, G. Bičkauskaitė, R. Gadonas, and S. Juodkazis, Mechanisms of three-dimensional structuring of photo-polymers by tightly focussed femtosecond laser pulses, Opt. Express 18(10), 10209-10221 (2010).

[79] M. Malinauskas, P. Danilevicius, and S. Juodkazis, Three-dimensional micro-/nano-structuring via direct write polymerization with picosecond laser pulses, Opt. Express 19, 5602-5610 (2011).

[80]I. Wang, M. Bouriau, L. Baldeck, C. Martineau, and C. Andraud, Three-dimensional microfabrication by two-photon-initiated polymerization with a low-cost microlaser, Opt. Lett. 27, 13481350 (2002).

[81] M. Thiel, J. Fischer, G. von Freymann, and $M$. Wegener, Direct laser writing of three-dimensional submicron structures using acontinuouswave laser at $532 \mathrm{~nm}$, Appl. Phys. Lett. 97, 221102 (2010).
[82] M.Emons, K. Obata, T. Binhammer, A. Ovsianikov, B. Chichkov, and U. Morgner, Two-photon polymerization technique with sub-50 $\mathrm{nm}$ resolution by sub-10 fs laser pulses, Opt. Mater. Express 2(7), 942-947 (2012).

[83] M. Malinauskas, V. Purlys, M. Rutkauskas, A. Gaidukevičiutè, and R. Gadonas, Femtosecond visible light induced two-photon photopolymerization for $3 \mathrm{D} \mathrm{micro/nanostructuring} \mathrm{in} \mathrm{pho-}$ toresists and photopolymers, Lith. J. Phys. 50(2), 201-208 (2010).

[84] A. Ovsianikov, Investigation of two-photon polymerization technique for applications in photonics and biomedicine, PhD Thesis (Leibniz Universitat Hannover, 2008) pp. 1-116.

[85] M. Malinauskas, V. Purlys, M. Rutkauskas, and R. Gadonas, Two-photon polymerization for fabrication of three-dimensional micro- and nanostructures over a large area, Proc. SPIE 7204, 72040C (2009).

[86] K.-S. Lee, P. Prabhakaran, J. Park, R. Kim, N. Cho, D.-Y. Yang, S. Park, T. Lim, S. Yong, and H. Kong, Recent advances in two-photon lithography, in: CIF'8 Proceedings (2008).

[87]H.-B. Sun, K. Takada, M.-S. Kim, K.-S. Lee, and S. Kawata, Scaling laws of voxels in two-photon photopolymerization nanofabrication, Appl. Phys. Lett. 83, 1104 (2003).

[88]3DPoli@gmail.com

[89]J. Trull, L. Maigyte, V. Mizeikis, M. Malinauskas, S. Juodkazis, C. Cojocaru, M. Rutkauskas, M. Peckus, V. Sirutkaitis, and K. Staliunas, Formation of collimated beams behind the woodpile photonic crystal, Phys. Rev. A 84, 033812 (2011).

[90] L. Amato, Y. Gu, N. Bellini, S.M. Eaton, G. Cerullo, and R. Osellame, Integrated three dimensional filter separates nanoscale from microscale elements in a microfluidic chip, Lab Chip 12, 1135-1142 (2012).

[91]A. Ovsianikov, A. Deiwick, S.V. Vlierberghe, P. Dubruel, L. Moller, G. Drager, and B. Chichkov, Laser fabrication of three-dimensional CAD scaffolds from photosensitive gelatin for applications in tissue engineering, Biomacromolecules 12(4), 851-858 (2011).

[92]S. Passinger, M. Saifullah, C. Reinhardt, K. Subramanian, B. Chichkov, and M. Welland, Direct 3D patterning of $\mathrm{TiO}_{2}$ using femtosecond laser pulses, Adv. Mater. 19, 1218-1221 (2007).

[93] M. Hermatschweiler, A. Ledermann, G. Ozin, M. Wegener, and G. von Freymann, Fabrication of silicon inverse woodpile photonic crystals, Adv. Funct. Mater. 17, 2273-2277 (2007).

[94]K. Terzaki, N. Vasilantonakis, A. Gaidukeviciute, C. Reinhardt, C. Fotakis, M. Vamvakaki, and M. Farsari, 3D conducting nanostructures 
fabricated using direct laser writing, Opt. Mater. Express 1(4), 586-597 (2011).

[95]B. Bhuian, R. Winfield, and G. Crean, Laser polymerization-based novel lift-off technique, Appl. Surf. Sci. 255, 5150-5153 (2009).

[96] A. Ovsianikov, J. Viertl, B. Chichkov, M. Oubaha, B. MacCraith, I. Sakellari, A. Giakoumaki, D. Gray, M. Vamvakaki, M. Farsari, and C. Fotakis, Ultralow shrinkage hybrid photosensitive material for two-photon polymerization microfabrication, ACS Nano 2(11), 2257-2262 (2008).

[97]M. Malinauskas, A. Zukauskas, V. Purlys, A. Gaidukeviciute, Z. Balevicius, A. Piskarskas, C. Fotakis, S. Pissadakis, D. Gray, R. Gadonas, M. Vamvakaki, and M. Farsari, 3d microoptical elements formed in a photostructurable germanium silicate by direct laser writing, Opt. Laser Eng. 50(12), 1785-1788 (2012).

[98]E. Brasselet, M. Malinauskas, A. Žukauskas, and S. Juodkazis, Photopolymerized microscopic vortex beam generators: precise delivery of optical orbital angular momentum, Appl. Phys. Lett. 97(21), 211108 (2012).

[99] A. Zukauskas, M. Malinauskas, C. Reinhardt, B. Chichkov, and R. Gadonas, Closely packed hexagonal conical microlens array fabricated by direct laser photopolymerization, Appl. Opt. 51(21), 4995-5003 (2012).

[100] M. Malinauskas, A. Zukauskas, V. Purlys, K. Belazaras, A. Momot, D. Paipulas, R. Gadonas,

A. Piskarskas, H. Gilbergs, A. Gaidukeviciute, I. Sakellari, M. Farsari, and S. Juodkazis, Femtosecond laser polymerization of hybrid/integrated micro-optical elements and their characterization, J. Opt. 12, 124010 (2010).

[101] M. Malinauskas, A. Zukauskas, K. Belazaras, K. Tikuisis, V. Purlys, R. Gadonas, and A. Piskarskas, Laser fabrication of various polymer micro-optical components, Eur. Phys. J. Appl. Phys. 58, 20501 (2012).

[102] A. Zukauskas, M. Malinauskas, L. Kontenis, V. Purlys, D. Paipulas, M. Vengris, and R. Gadonas, Organic dye doped microstructures for optically active functional devices fabricated via two-photon polymerization technique, Lith. J. Phys. 50(1), 55-61 (2010).

[103] P. Abgrall and A.-M. Gue, Lab-on-chip technologies: making a microfluidic network and coupling it into a complete microsystem, J. Micromech. Microeng. 17(15), 15-49 (2007).

[104] G. Barillaro, S. Merlo, S. Surdo, L. M. Strambini, and F. Carpignano, Integrated optofluidic microsystem based on vertical high-order one-dimensional silicon photonic crystals, Microfluid. Nanofluid. 12, 545-552 (2012).

[105] X. Zhang, L. Ren, X. Wu, H. Li, L. Liu, and L. Xu, Coupled optofluidic ring laser for ultrahigh-sensitive sensing, Opt. Express 19(22), 22242-22247 (2011).

[106] Y. Xia and G.M. Whitesides, Soft lithography, Annu. Rev. Mater. Sci. 28, 153-184 (1998).

[107] S. Rekstyte, A. Zukauskas, V. Purlys, Y. Gordienko, and M. Malinauskas, Direct laser writing of $3 \mathrm{D}$ micro/nanostructures on opaque surfaces, Proc. SPIE 8431, 843123 (2012).

[108] E. Stankevicius, T. Gertus, M. Rutkauskas, M. Gedvilas, G. Raciukaitis, R. Gadonas, V. Smilgevicius, and M. Malinauskas, Fabrication of micro-tube arrays in photopolymer SZ2080 by using three different methods of a direct laser polymerization technique, J. Micromech. Microeng. 22(6), 065022 (2012).

[109] M. Malinauskas, P. Danilevičius, D. Baltriukiene, M. Rutkauskas, A. Žukauskas, Ž. Kairytè, G. Bičkauskaitè, V. Purlys, D. Paipulas, V. Bukelskienè, and R. Gadonas, 3D artificial polymeric scaffolds for stem cell growth fabricated by femtosecond laser, Lith. J. Phys. 50(1), 75-82 (2010).

[110] P. Danilevicius, S. Rekstyte, E. Balciunas, A. Kraniauskas, R. Jarasiene, R. Sirmenis, D. Baltriukiene, V. Bukelskiene, R. Gadonas, and M. Malinauskas, Micro-structured polymer scaffolds fabricated by direct laser writing for tissue engineering, J. Biomed. Opt. 17(8), 081405 (2012).

\title{
NANOFOTONINE் LITOGRAFIJA - UNIVERSALUS BŪDAS FUNKCINIAMS TRIMAČIAMS MIKRODARINIAMS IR NANODARINIAMS FORMUOTI
}

\author{
M. Malinauskas, G. Kiršanskè, S. Rekštytė, T. Jonavičius, E. Kaziulionytė, L. Jonušauskas, \\ A. Žukauskas, R. Gadonas, A. Piskarskas
}

Vilniaus universiteto Fizikos fakulteto Kvantinès elektronikos katedra ir Lazeriniu tyrimu centas, Vilnius, Lietuva

\section{Santrauka}

Pristatomas tiesioginès lazerinès polimerizacijos metodas, pateikiama išsami literatūros apžvalga, palyginamos trimačių mikrodarinių ir nanodarinių formavimo alternatyvios technologijos, paaiškinami fizikiniai principai ir taikymo galimybès. Visa tai paremta originaliais ekspe- rimentiniais autorių gautais rezultatais. Darbe parodomi funkcinių trimačiu polimerinių mikrodarinių ir nanodarinių pavyzdžiai, apibūdinamas jų veikimas. Pirmąkart pademonstruojama opto-fluidinio lusto lazerinio formavimo ir jo perkèlimo ant kito padèklo bei integruotos trimatès mikro-elektro grandinès igyvendinimo galimybès. 